\title{
Reorganising the Military Institutions and National Security Strategy
}

\author{
Mohd. Rizwan* \\ Department of Defence Studies, Meerut College Meerut, (U.P.) India \\ Email Id:drrizwanmom@gmail.com
}

\begin{abstract}
India has emerged as a leading military, economic and diplomatic power in present era, it has world's second largest population as well many internal and external security challenges of various dimensions. In present circumstances it's a big responsibility of the policy makers to meet all the security threats and challenges successfully, this paper deals with all possible aspects of the challenges and policies needed to be opted to safeguard our comprehensive interests.

Keywords: National Security Strategy (NSS), Military Institutions, Militarisation, Defence management, Ministry of Defence $(M o D)$, Defence Research and Development Organisation (DRDO).
\end{abstract}

\section{PAPER/ARTICLE INFO} RECEIVED ON: 10/09/2019 ACCEPTED ON: 23/11/2019

Reference to this paper should be made as follows:

Mohd. Rizwan (2019),

"Reorganising the Military Institutions and National Security Strategy", Int. J. of Trade and Commerce-IIARTC, Vol. 8, No. 2, pp. 363-372 


\section{INTRODUCTION}

India simultaneously faces a period of strategic opportunity and confronts tremendous threats and challenges in safeguarding its vital national interests such as elimination of terrorism, internal cohesion, peaceful neighborhood and the like. It has to cope with prevailing uncertainty and global shift in balance of power and persisting external threats. More importantly, despite overall impressive economic growth, the domestic threats and challenges have the potential of limiting the rise of India. As it grows economically and gains greater geo-political heft it will be required to play a more proactive role on the world stage. It is incumbent upon the leadership, therefore, to clearly specify our ends through national vision, interests and objectives to the world and synergies means of application of instruments of our national power to achieve the desired ends. India needs a National Security Strategy (NSS) that takes care of present day security threats and potential challenges to national security and safeguard national interests. The strategy is all about the way the country will use the means available to it to exercise control over set of circumstances to achieve its objectives. Institutions play an important role in formulation and execution of strategy. India has no clearly articulated NSS, and this mainly is the outcome of institutional weakness. This weakness has also resulted in sub-optimal military effectiveness in India. Military institutions influence military effectiveness which in turn affects the outcome of security goals set by NSS. Besides, by ensuring efficient utilisation of resources without compromising the quality of military power, institutions help availability of resources for meeting social goals set by NSS. Thus, reforming military institutions is necessary for success of NSS. Institutional behavior is not easy to change but it is essential for India's national security. This paper begins with the attempt to define national security and examination of the concept of national security and then examines the concept of military effectiveness and role of institutions in ensuring that. It then identifies India's national interests, and existing threats and potential challenges to the nation's security which must be addressed. In the subsequent paragraphs, present institutional shortcomings and their indicators are enumerated before recommending the reforms that must be taken to ensure national security. The paper ends by highlighting impediments to change.

\section{DEFINITION AND CONCEPT OF NATIONAL SECURITY}

There is no single universally acceptable definition of the term national security. A simple yet broad definition is the 'quality or state of being secure from danger or anxiety'. For social scientists it means 'The ability of a nation to protect its internal values from external threats'. The noted American diplomat and scholar George Kennan provided a crisp definition of national security, in American context, as "the continued ability of this country to pursue internal life without serious interference." The American Journalist Walter Lippman defined it thus, "a nation has security when it does not have to sacrifice its legitimate interests to avoid war, and is able, if challenged, to maintain them by war." The British political scientist Barry Buzan defines security as 'the pursuit of freedom from threat and the ability of states and societies to maintain their independent identity and their functional integrity against forces of change which they see as hostile." A sample of these definitions would point to the difficulty in defining the term and the concept of national security. It remains a weakly conceptualised, ambiguously defined, but politically powerful concept. The scope of national security has expanded over time. Presently, 
the concept of national security includes all those aspects which are critical for a nation's survival, growth and well being and for ensuring which a country is prepared to use all the tools of diplomacy, persuasion, coercion, threat or use of force. Military security, an essential element of national security, is a function of military effectiveness; which itself stems from military doctrines, capability and readiness in terms of cost and effort.

\section{CONCEPT OF MilitARY EFFECTIVENESS}

A traditional instrument available to a sovereign state to provide security for its citizens are its armed forces. They serve to defend the nation's vital interests. These are traditionally summarized as defending the territorial integrity of the nation and its way of life, provide muscle to the nation's diplomacy and safeguard its economic interests from hostile external environment. To be able to perform its assigned role the military has to be effective. Military effectiveness as defined in 'Creating Military Power-The Sources of Military Effectiveness', as "the capacity to create military power from a state's basic resources in wealth, technology, population size and human capital". It can be assessed by looking at four central attributes: Integration - i.e. synergies within and across levels of military activity and avoidance of Counterproductive Actions; Responsiveness-'i.e. 'ability to tailor military activity to the state's own resources, environmental constraints (both internal and external), opportunities to its adversary's strengths and weaknesses in preparing for war; Skill - ability to assimilate new technologies or to adapt to sophisticated doctrine and demanding forms of military organisation, including the capacity to ensure that military personnel are motivated and prepared to execute tasks on the battlefield; and Quality - or the capacity of the state to supply itself with essential weapons and equipment at economical rates. The more the military exhibits these attributes, the more capable it is at generating military power. In nut shell, how well a state uses the resources available to it determines its military's effectiveness. The military institutions are involved in mobilising resources and determining their use for generating maximum military effectiveness. Effectiveness in a very large measure is a function of robustness and efficiency of institutions and its purpose is to serve national interests.

\section{INDIA'S NATIONAL SECURITY INTERESTS}

Let us begin by recapitulating the idea of national interests and then define India's major national security interests which need to be guarded. The four basic national interests of nation states are the defence of the homeland, economic well being, the creation of a favourable world order or external environment and the promotion of national values. These national interests are generally graded on a three or four-tiered scale of priorities or intensities as survival and/or vital, major and peripheral interests. The most basic and abiding national interest is the survival of the state. All other interests can and do change in intensity or priority from time to time. The sub-divisions tend to be judgmental. I have only covered India's vital interests here. In my view, India's first order national interests include: security of India's sovereign territory with its values intact (survival of the state); internal stability and security; elimination of terrorism and violent religious extremism; creation of a secure environment conducive for sustained economic development; access to all sources of energy; free flow of commerce; stable international economic order and financial systems ; non-discriminatory access to scientific and technological progress : peace and stability in its immediate neighbourhood and Indian Ocean Region and autonomy in decisionmaking. 
In security terms, our vital national security interests are: protection of our sovereignty and territorial integrity, protection of lives and property of our citizens against external aggression and terrorism, deterrence against the use or threat of use of weapons of mass destruction; preventing establishment of foreign military presence and ensure state stability in our immediate neighbourhood and finally, ensure security of sea lanes of communication. It is in the context of these interests that threats and challenges to India's security are examined.

\section{Threats and Challenges and India's National Security Strategy}

Since National Security Strategy must take care of present day security threats and potential challenges it is necessary to identify these as follows:

\section{(A) Current Threats/Challenges.}

(i) Pakistan. Pakistan is the source of immediate direct threat. Keeping in mind Indiacentricity of Pakistan's foreign and security policy it would be safe to presume that it is likely to persist with proxy war, as a corner stone of its India containment strategy. This threat is exacerbated by US need to accommodate Pakistan because of its dependence on the country to prosecute the war in Afghanistan and continued support from China. Its nuclear capability and calculated low threshold for use of nuclear weapons continue to limit India's options in dealing with it.

(ii) China. In the near term, threat from China exists in terms of possible border tensions, diplomatic spats and incremental growth of China's footprint in our immediate neighbourhood. A clash of interest can also occur in the IOR as China increases its forays or questions growing Indian power and legitimacy. Moreover, cyber and space based threats are both near and real.

(iii) Internal Threats. Internal security is the greatest challenge facing India today. Festering insurgencies in the North East and J\&K and Left Wing Extremism make India look like a state under siege. The reasons for these developments are complex and can be traced to the cumulative outcome of Pakistan's use of terror as a weapon, poor governance, criminalisation and communalisation of politics, increasing social awareness and failure of the state to provide economic benefits to the deprived. Networking of externally inspired and supported terrorism with domestic terror groups makes this threat even more potent.

(B) Medium and Long-Term Threats/Challenges.

(i) China. China's capabilities are growing at a rapid pace and difference in comprehensive national power vis-à-vis India is increasing. China's intentions are, however, not clear and we have to consider the possibility of a negative change in the Chinese posture. China's posture could change in the event of a political upheaval in that country or if the power asymmetry increases dramatically. Despite growing economic interaction and commonality of interests on certain global issues such as climate change, there are a large number of issues between the two countries, which if not managed with prudence, could cause conflict and more importantly, confrontation. Conventional military conflict between India and China is by no means inevitable. Although a credible nuclear deterrence on part of India may appear to discount the possibility of a major war being initiated against India but a limited or localised war with the aim of showing India as a peace loving state is very much possible. India's propensity for strategic restraint, its high nuclear threshold and China's 
history of brinkmanship displayed during Korean War and Sino-Soviet conflict in 1969 support this hypothesis.

(ii) Energy Security. Due to rising demand, competition for sourcing energy resources will be a challenge for most import dependent countries. Turbulence in the Middle East may further contribute to energy insecurity and military involvement of external powers to secure energy resources from the region will also create a direct security challenge to India. Due to India's energy dependence on the region and the presence of about five million strong Indian diaspora in the region, any conflict there will also present a serious social and economic challenge to India.

(iii) Maritime Security. India's continued economic growth will depend more and more on increased trade, import of energy resources and raw materials. Security of its island territories and of sea lanes of communication will be of critical importance to India. Other major powers will also face this criticality. The perception of vulnerability and power play in the IOR has the potential of causing serious security challenge for India.

(iv) Insecurity and instability in the Immediate Neighbourhood. This remains a real medium and long-term challenge. Weak political institutions and poor capacity of states combined with rising population, internal dissonance, rising trend of religious fundamentalism and ethnic or sectarian violence may cause serious internal instability in India's neighbourhood. Our adversaries may attempt to make further inroads into these countries and pose a security threat to India.

(v) Militarisation of Space and Cyber Security. The apparent stability of the nuclear balance and the quest for seeking new sources of military advantage may prompt some states to move towards weaponisation of space. India, with its limited space capability, will face a major challenge in protecting its space assets in case of a conflict. Similarly, cyber security will be a greater challenge going forward- both for security and economy.

\section{INDiA's NATIONAL SECURITY STRATEGY}

National Security Strategy is the outcome of a long-term vision. Envisioning any long-term perspective calls for a deep and involved thought process. For a country of our size and stature, institutionalised strategic thinking mechanism within and outside government is inadequate. India has never had a coherently articulated national security strategy; certainly not in the public domain. Tanham rightly suggests that "overtime, a set of policies and strategies evolved informally to deal with complex strategic dilemmas related to internal unity and potential threats from abroad." However, the general contours of India's NSS can be pieced together from the speeches of its leaders on various occasions and perception of its strategic thinkers. India seeks to achieve its national security interests through rapid and sustained economic growth to reduce social inequality and regional imbalances; influence events to engender stability and security in the neighborhood; create a favorable external environment for continued economic growth; develop adequate military power to deter external aggression or coercion and secure its energy and resources supply, and ; create conditions for India's rise as an important player in international affairs consistent with its values of democracy, pluralism, secularism and rule of law. Let us now examine the shortcomings of its military institutions have affected India's national security interests. 


\section{WHAT ARE THE SHORTCOMINGS?}

Some of the major indicators of the shortcomings are: an inability to alter strategic behaviour of Pakistan and China and ineffectiveness of strategic deterrence ; inadequacy of the existing doctrines and lack of higher direction in framing them resulting in failure to generate workable alternatives in the face of crises like in 2002 and 2008; stalled or imbalanced modernisation; continued reliance on imports for military equipment; inefficient logistics set up for want of synchronisation of operational and logistics plans and inter-service differences; inordinately long time taken to bring under control festering insurgencies; lack of surgical strike capability; failure to groom and produce highly competent leaders, and; deterioration in quality of life and work environment reflected in persisting shortage of officers in all three services. The net result is that we have a large military establishment but not well equipped and is sub-optimally organised to meet the existing and emerging threats in a cost effective manner. The shortcomings in India's defence management originate from organisational inadequacy, lack of directional control, intellectual stagnation and frictions among institutions. Some of these shortcomings are internal to the armed forces but most of them result from lack of appreciation, at the highest level, of the use of force as a useful instrument of politics and therefore abysmal lack of higher direction. Security policy-if it exists has become subservient to foreign policy. The responsibilities to formulate and coordinate defence policy are fragmented and ill defined resulting in lack of accountability and therefore, poor outcomes. The NSA, who should organise and coordinate national security management on behalf of the Prime Minister, think ahead and work as a forward planner on national security, is saddled with executive responsibilities and diplomatic fire fighting; the Ministry of Defence lacks human and intellectual capacity to formulate and execute defence policy; the Department of Defence Finance functions as an instrument of obstruction on behalf of the Finance Ministry to delay any kind of defence spending; the DRDO neither develops reliable military systems nor permits their import in time and the procurement process is beset with chronic delays, inefficiency and allegations of corruption. On their part, the services are loath to review their organisations, generally dislike jointness and integration due to perceived loss of influence; have an ageing leadership profile with inadequate tenures in command assignments, lack systematic leadership development and education plans, suffer from narrow regimental loyalties, give no room for innovative thinking and above all have developed tolerance for corruption.

\section{NEED OF INSTITUTIONAL REFORMS}

Analysis of the shortcomings mentioned earlier also point to the path of reforms. Let me briefly describe the institutional reforms essential for achieving military effectiveness in India at two levels viz; at governmental level and within the military establishment.

\section{(A) At Governmental Level.}

(i) Articulation of National Security Strategy. There is a need to clearly articulate national security strategy which can form the basis for drawing up national military strategy, long term perspective plan, force development plan, acquisition plan, etc. The organisation mandated to formulate NSS must have domain knowledge of all aspects of national security, emerging challenges posed by geo-political alignments, technological 
developments affecting the nature of warfare, ever changing concepts of deterrence and the like. NSCS is obviously best suited for this task.

(ii) Civil Military Relations. Sound security strategy requires that military considerations be integrated with non-military concerns involving diplomacy, economic policies and domestic policies. Civil-military conflict can interfere with the smooth functioning of senior policy-making institutions and thereby undermine national strategy. To bring disparate elements together requires close cooperation and frank, honest exchanges between civilian and military leaders.

(iii) Higher Defence Management. There is no single or competent agency to lay down defence policy and no coordination between various agencies such as Ministries of Home Affairs, External Affairs, Finance, Defence and intelligence services. The National Security Council Secretariat (NSCS) has to have an effective military component to advise on security issues. Chief of Defence Staff (CDS) needs to be appointed to overcome inter-service differences and render single point military advice to the Cabinet Committee on Security (CCS). Integration of the Ministry of Defence and services headquarters is also essential for formulation of sound defence policy. There is also a need for creation of a cadre of civil servants specialising in matters of security. Officers so selected should be assigned only to Ministries of Defence, Home, Finance, NSCS and Cabinet Secretariat. This will provide some continuity and facilitate capacity building. The Armed Forces must be an integral part of the 'decision-making' process on issues of national security that involve them, directly or indirectly.

(iv) Formulation of Clear Military Doctrines. This issue is relevant at both, governmental and military levels. The doctrines have to be integrated with the political objectives that India seeks to achieve. There is a need to define the political objectives, analyse security dilemma of the adversaries, understand constraints of resources, structure armed forces to meet specified ends and develop doctrines that best meet the political objectives. Politico-military congruence is therefore a must.

(v) Resolving Procurement Dilemma. This issue which impacts defence preparedness in a major way requires reforms at the policy level in determining the role and accountability of DRDO, involving domestic industry in research \& development and defence production and prioritising of acquisitions based on current and future needs. Only the political leadership can resolve inter-institutional and inter-service differences in this sphere.

(vi) Manpower Policy. The officer profile in the three services is a matter of concern. Not only there is shortage at critical level but the quality and age profile at senior levels is unsatisfactory. Due to very short tenures at higher levels, senior commanders can hardly influence their respective commands and are constantly anxious about their next promotion. There is a lack of continuity even in critical appointments thus affecting any forward thinking and long term policy planning. The government needs to step in to ensure that the age profile of senior officers is brought down in a time bound manner.

(vii) Integration and Jointness. Here it will be worthwhile to quote Admiral Sureesh Mehta, "Today, the scope of activity of the Indian Armed Forces ... ranges from internal security tasks, augmenting diplomatic effort, bilateral and multilateral cooperative efforts with other 
countries, humanitarian assistance and disaster relief and go on to cover the entire range of tasks across the full spectrum of conflict. The need for greater integration of the Armed Forces with the MoD, and External Affairs, as well as establishment of effective coordination mechanisms with several other ministries and agencies, is therefore incontestable amongst the Services, as we develop leaders, organisations, systems and doctrines, we must continue to strengthen trust and confidence amongst the Services and between Service components that are committed to joint operations." Integration and jointness are as much required between the Service Headquarters and MoD, as amongst the Services. Considering inter-service rivalries, this process will be the necessity and have to be top driven.

(B) Reforms at Services Level.

(i) Preventing Wasteful Expenditure. India's developmental needs will be high in the foreseeable future and the defence allocation is unlikely to be raised much beyond present levels in terms of percentage of GDP. Considerable scope to improve the quality and efficiency of defence expenditure exists both, on revenue and capital expenditure sides. Review of organisations and establishment of joint inter-services logistics, training institutions and functional commands can save major manpower costs. Better management of inventories, prevention of corruption in procurement and works through improvements in procedures and practices and better project management can spare funds for modernisation. Instead of procuring highly expensive legacy systems, services need to focus on niche capabilities and systems which will be appropriate to meet potential threats. Adoption of a Performance Based Logistics (PBL) strategy under which the original manufacturer or its nominated contractor maintains the weapon system at the specified level of operational readiness and usage would also help.

(ii) Military Education. India's military institutions are good at imparting professional skills but do not educate its future military leaders in military history, strategy, doctrines, or creating understanding of geopolitics, economy and much else that is required. Every officer needs to be capable of analyzing the trends and apply theory into practice realistically. Education, with its focus on intellectual development, is the need of the hour.

(iii) Leadership Development. The future, considering its expected complexity, ambiguity and turbulence, will demand extraordinary leadership - especially strategic leadership throughout the military. The leadership development process must result in leaders who are competent, have the right education and experience through academic and professional education and then the service experience through appointments tenanted. Ability to articulate one's honest views must be encouraged. Strategic literacy is needed if military leaders are to provide sound strategic advice to the political leadership.

The reforms, if carried out in a comprehensive and sustained manner, will generate unity of purpose, make institutions accountable and responsive, create strategic options, enhance India's military effectiveness and, make deterrence credible.

It will not only help to create a favourable external and domestic environment for stability and growth but also engender a feeling of security amongst the citizens by reducing their fear and anxiety. 


\section{Difficulties that Stand in the Way of Reforms}

In independent India's history defence reforms at some scale were attempted only twice. The first attempt was led by the then Defence Minister, Mr Y B Chavan when rationalisation of the military and civil structures in Ministry of Defence was carried out, logistic services were overhauled and shortages of weapons and equipment started to be made up through re-prioritising the activities of domestic defence enterprises and opening up of foreign sources. The second attempt at reforms started in 1980s when under the guidance of Gen Sundarji the mechanisation of the Army took place, operational concepts and doctrines were revised and new weapon systems were inducted. These two instances indicate that the reforms in India's defence structure were mainly personality driven. Crisis can also force reforms like it did in the wake of 1962 War yet the lessons drawn from the reform process that followed Kargil conflict does not inspire confidence. The institutional reforms have, however, never been attempted in a meaningful way. The Need for reforms does not mean they will automatically take place. Here I make use of the theory of Path Dependence-mainly applied in economic field, to explain my scepticism. This theory explains how the set of decisions one faces for any given circumstance is limited by the decisions one has made in the past, even though past circumstances may no longer be relevant. Inferior standards can persist simply because of the legacy they have built up. Besides, our common culture of low expectations from institutions of state, self-before-society and, tolerance for sub-optimal outcomes will prevent any long lasting reform process to take hold. The prevailing system of authority without accountability is difficult to change without external direction and coercion since those who benefit from it are least likely to support the change.

\section{CONCLUSION}

The international environment India faces and is likely to face in the years ahead requires a well formulated security strategy with effective military power to back it. Writers and thinkers from within India and abroad have been opining that India has failed to build a first-rate military with strategic reach and an independent deterrent. Because of disconnect between the political and military leadership and in the absence of an articulated NSS there is no common view of national security. Due to lack of strategic vision and higher direction the institutions work in water tight compartments without coordination. The practice of strategic restraint has transformed into a strategic constraint. Inter-service rivalries prevent them from integrating their headquarters, logistic infrastructure, training institutions and developing joint doctrines. What we need is a strategically effective military: an instrument of power capable of serving the national interests of India in a competent and cost effective manner. Institutional reforms are, therefore, crying need of the hour. Besides the difficulty in changing strategic culture at directional level even military organisations are often conservative and risk-averse and, thus, are typically resistant to change, especially disruptive change, since it can threaten the stability of normal day-to-day operations, standard operating procedures, war plans and even career paths. Both institutions and belief systems have to change for successful reform since it is the mental models of the actors that will shape choices. This is a difficult but not an impossible task. 
Reorganising the Military Institutions and National Security Strategy

Mohd. Rizwan

\section{REFERENCES}

[1]. Melkote, Rama and Rao, Narsimha (1997). International Relations (Revised and Enlarged Edition) by Sterling Publishers, New Delhi.

[2]. McMellan, Olson, Sondermann (1977). The Theory and Practice of International Relations (Fourth Edition) Prentice Hall of India, Pvt. Ltd.

[3]. Malhotra, V.K. (2014). International Relations (Fourth Edition) by Anmol Publications, Pvt. Ltd, New Delhi.

[4]. www.thehindu.com/paper/national/papersnational-security.

[5]. www.megaessays.com.

[6]. www.idsa.com. 